\title{
The Mechanical Properties and Wearability of the Jacquard Fabrics with Differential Density for Tents
}

\author{
Yang Baoqing \\ Topsun New Material Research Institute \\ Zhejiang Topsun Leisure Products Co., Ltd., \\ Huzhou, P. R. China \\ e-mail: yang@hengfeng-china.com
}

\author{
Qin Yi \\ Topsun New Material Research Institute \\ Zhejiang Topsun Leisure Products Co., Ltd., \\ Huzhou, P. R. China \\ e-mail: george@hengfeng-china.com
}

\author{
Zhang Jinming \\ Topsun New Material Research Institute \\ Zhejiang Topsun Leisure Products Co., Ltd., \\ Huzhou, P. R. China \\ e-mail: cherry@hengfeng-china.com
}

\author{
Luo Zhihua \\ Topsun New Material Research Institute \\ Zhejiang Topsun Leisure Products Co., Ltd., \\ Huzhou, P. R. China \\ e-mail: reform-luo@163.com
}

\begin{abstract}
The mechanical, wear-resisting properties and air permeability of a kind of novel jacquard fabrics with differential warp density for tents were studied. The results showed that the strength of the filament and warp density took a great role on the broken strength of the fabric and the order of tensile strength for different part is as follow: $\mathrm{C}>\mathrm{D}>\mathrm{A}>\mathrm{B}$. The bending stiffness of tinsel thread and tensile strength in radial direction played a great role on the bursting strength of the tent. After friction for 3200 times, the weight loss in Part $A$ is only about $2.5 \%$, showing an excellent wear-resisting property. However, the wearresisting property in Part $\mathrm{C}$ and $\mathrm{D}$ is very poor. For all parts of the fabric, the air permeability is no more than $140 \mathrm{~mm}$, and that in Part $C$ and $D$ is less than 120mm, displaying a better warm and windproof property.
\end{abstract}

Keywords-mechanical properties; wear-resisting property; air permeability; jacquard fabrics; tent)

\section{INTRODUCTION}

In recent years, outdoor sports in our country as a new way of movement, got the interest of many sports fans, is no longer the rights of the professional [1]. With the advocacy initiatives of "Decompression, release", the outdoor sports has become a kind of social fashion, is more accepted by the people of different age, class, occupation. The characteristic of outdoor sports such as popularization, adaptation, is more significant. Outdoor sports that is engaged in outdoors in all kinds of sports, is a personal hobby with the combination of sports and tourism and its content is very wide, such as mountain climbing, camping, rock climbing, horse riding, rafting, skiing, gliding, parachuting, bike, independent hostels and backpackers hostels, etc [2]. Outdoor sports clothing and shelter has become the main outdoor sports equipment [3].

Due to the two features of outdoor and sports for tent fabrics, the requirement is also relatively strict and demanding [4-8]. When we take part in outdoor sports, a heavy down jacket or vest may cause you to overheat and these activities will make you sweaty, which need the fabric with good heat dissipation and ventilation performance. Outdoor sports inevitably encounter rain or snow fog, and the fabrics for tents with waterproof properties [9]. It's considerably windier and colder, which the fabrics for outdoor need warmth retention properties. The washing conditions in outdoor is limited and the fabrics for outdoor should have the antibacterial and selfcleaning functions $[10,11]$. Outdoor activities such as rock climbing, the tensile, tearing resistance and wear resistance properties of fabrics are higher [12].

In conclusion, the requirements for outdoor sports fabric and tent fabric should have more functions. However, it is very demanding from the perspective of textile technology and even some indicators are conflicting. In this paper, the mechanical properties, wearing resistance and air permeability of the fabric, which is a kind of novel jacquard fabrics with differential warp density for tents, are studied and the experimental and theoretical basis will be provided for the application as tents.

\section{EXPERIMENTAL}

\section{A. Experiment Materials}

The jacquard fabrics with differential warp density are made of PET filament, tinsel, fancy yarns and colored thread. According to the warp density, the jacquard fabrics can be divided into four parts. The appearance of the novel jacquard fabrics is shown as Figure 1.

\section{B. Characterization}

- Measurement of tensile properties

All the treated samples were beforehand placed in constant temperature and humidity room $\left(\mathrm{T} 20{ }^{\circ} \mathrm{C}\right.$, Humidity 65\%) for 24 hours, and then the tensile properties of the industrial yarn of PET were conducted using an electronic universal tensile test device at a tensile 
speed of $50 \mathrm{~mm} / \mathrm{min}$ on the samples with an initial length of $100 \mathrm{~mm}$.

- Measurement of bursting strength

Firstly, put the specimen onto the ring and then the billiard would move perpendicular to the sample at a certain speed. When the central of the fabric surface was under vertical concentrated load, the yarn would be breaking within weak area which showed smaller deformation ability and lower strength. The diameter of sample was $60 \mathrm{~mm}$ and the speed of billiard was $100 \mathrm{~mm} / \mathrm{min}$.

- Measurement of wear-resisting property

The fluff experiments were carried out with one side of the nylon brush by YG501 pilling machine. Then, the nylon brush was changed into a ball with fabric and pilling test was experimented. According to national standard GB/T 4802.1-2008, the degree of wear-resisting property for jacquard fabrics will be shown by comparing the standard sample.

- Measurement of pilling resistance

The pilling experiments were carried out with one side of the nylon brush by YG501 pilling machine. Then, by taking photos with a digital camera the degree of pilling property for jacquard fabrics will be shown to assess the pilling resistance of each part.

- Measurement of air permeability

All the treated samples were beforehand placed in constant temperature and humidity room (T $20{ }^{\circ} \mathrm{C}$, Humidity $65 \%$ ) for 24 hours, and then measurement of air permeability was carried out by YG461 digital air permeability instrument. The size of the sample is $40 \mathrm{~cm} \times 40 \mathrm{~cm}$.

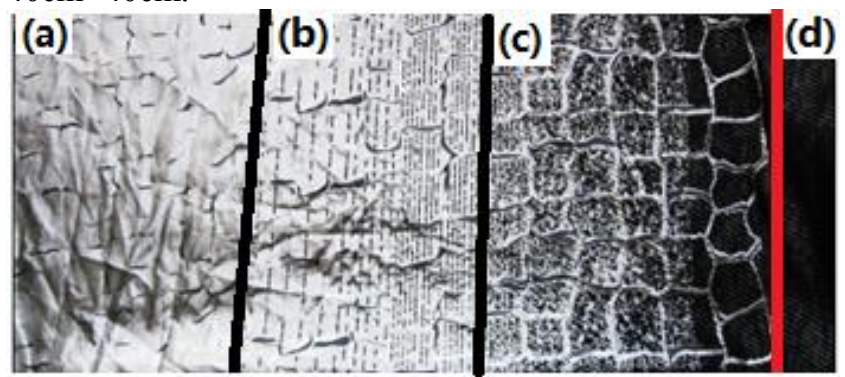

Figure1: the appearance of the novel jacquard fabrics

\section{RESULTS AND DISCUSSION}

Fig .2 shows the tensile properties of the jacquard fabrics in different parts. It showed us that the order of tensile strength for different part is as follow: $C>D>A>B$. It was found that the basic weave structure is same for four parts, and there is some tinsel thread used in Part $\mathrm{C}$ and Part D. On the one hand, the tensile strength of tinsel is larger than that of PET. More the content of tinsel is, the larger the strength of the fabric is. On the other hand, the tinsel thread increases the density of the fabrics. The density in Part $C$ is denser than that in Part $D$, resulting that the tensile strength in Part $\mathrm{C}$ is maximum. In Part A, it is found that there are some fancy yarns. Due to the present of fancy yarn, the original tightness of fabric is destroyed and the contact point between fancy yarn and basic weave makes the original fabric loose. Therefore, the tensile strength in Part B is much lower. In design fabrics for tents, it is found that the strength of the filament and warp density take a great role on the broken strength of the fabric.

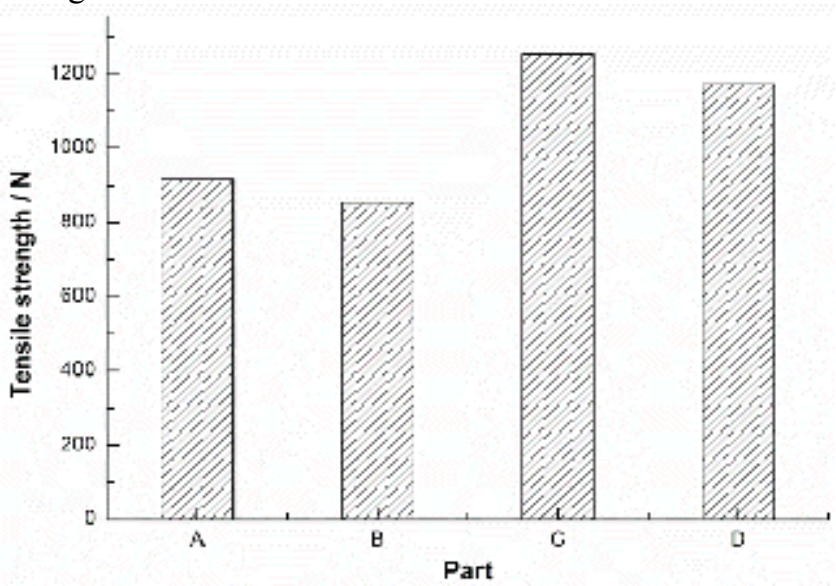

Figure 2: the tensile strength of the jacquard fabrics in different parts

Fig .3 shows the bursting strength of the jacquard fabrics in different parts. As can be seen from Fig.3, it is found that the bursting strength in Part A shows the maximum value. Part A is made of soft filament PET, there is not tinsel thread and fancy yarn and the structure of fabric is tight, showing the largest bursting strength. The bursting strength in Part B is less than that in Part A, because of the present of the a few fancy yarns. The tensile strength and bending stiffness of the PET is better than that of the fancy yarn. What is interest is that the Part $\mathrm{C}$ shows the minimum bursting strength. It is because that the tinsel has a great tensile strength, but the bending stiffness of tinsel thread and tensile strength in radial direction is poor. As a consequence, Part $\mathrm{C}$ shows the poor bursting strength. Thus, the bending stiffness of tinsel thread and tensile strength in radial direction play a great role on the bursting strength of the tent.

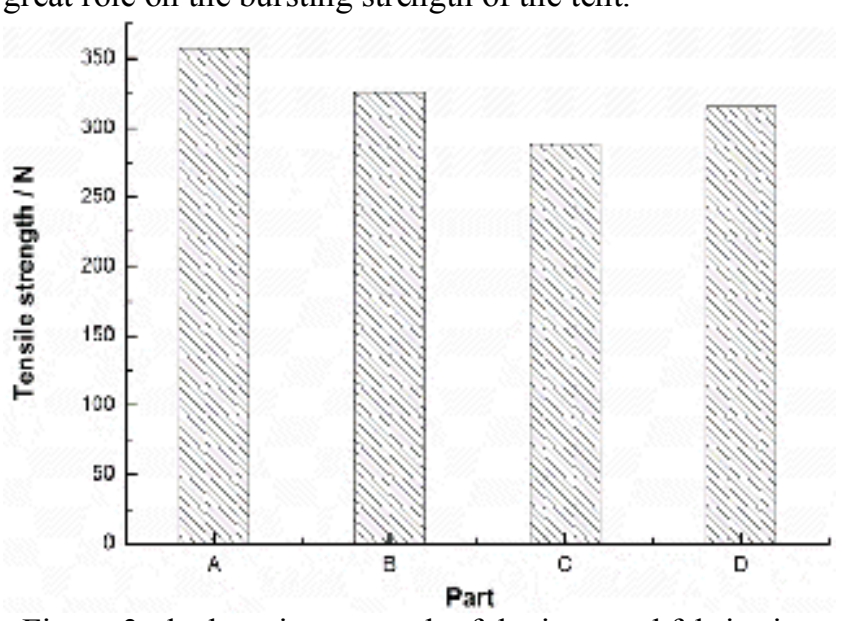

Figure 3: the bursting strength of the jacquard fabrics in different parts

Wear refers to the repeated friction between fabrics or with other substances and fabric will be destroyed by the gradually wear phenomenon. Smaller the weight loss is, the better the wear-resisting property of the fabric is. Figure 4 shows the wear-resisting property of the jacquard fabrics in different parts. As can be seen from Fig .4, with increasing the number of friction, the weight loss for all parts increases. After friction for 3200 times, the weight loss in Part A is only about $2.5 \%$, showing an excellent 
wear-resisting property. However, the weight loss in Part $\mathrm{C}$ and $\mathrm{D}$ is more than $30 \%$ and $40 \%$, respectively, indicating that the wear-resisting property in Part C and D is very poor. This phenomenon illustrates that the tinsel and yarns used in Part D shows a worse wear-resisting property.
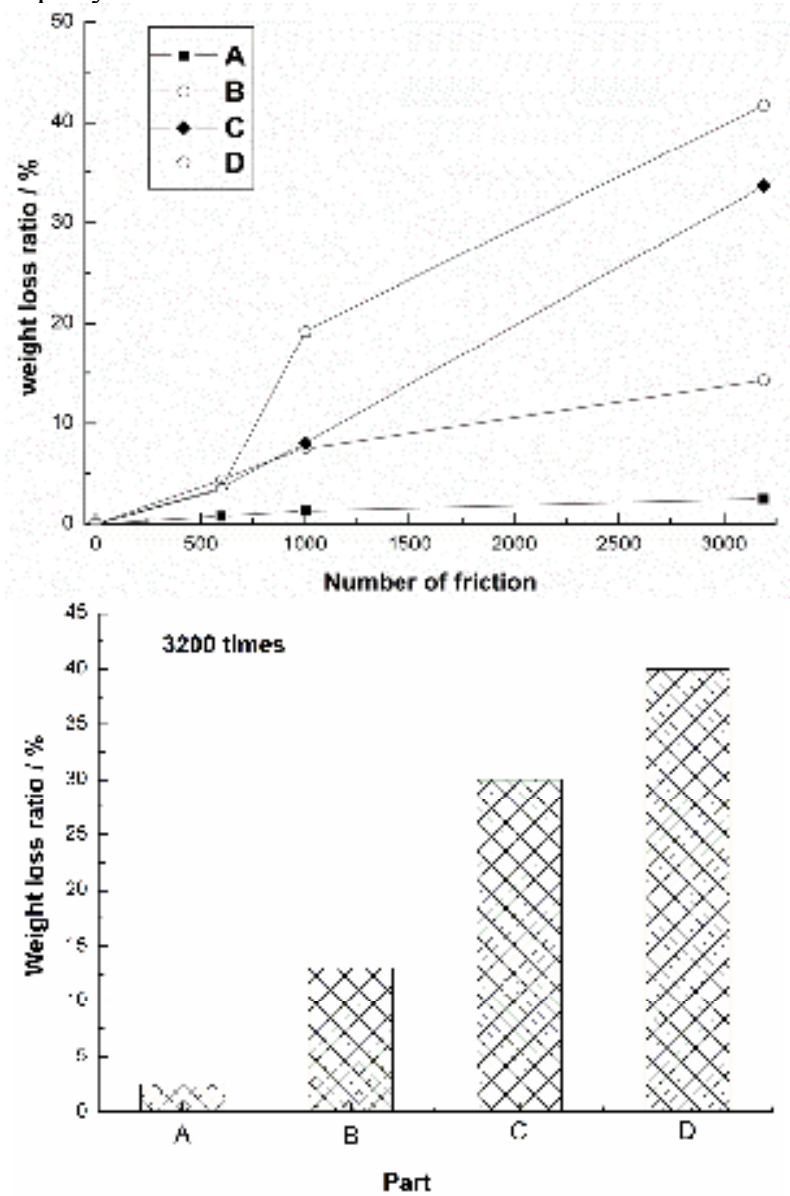

Figure 4: the wear-resisting property of the jacquard fabrics in different parts

For further study the wear-resisting property, the pilling resistance of the jacquard fabrics in different parts were analyzed and the results as shown in Fig .5. There are many factors which can influence the pilling performance of the jacquard fabrics, such as fiber, yarn structure, fabric structure, finishing condition and dressing condition. As can be seen from Fig .5, Part A is made of soft filament PET and there is not tinsel thread and fancy yarns. It is found that there is a little of hairiness, different size and density of the hair ball covering on the surface of the jacquard fabrics. Part B is made of soft filament PET and there are some fancy yarns. As shown in part B, the pilling performance of the jacquard fabrics is no obvious deterioration. Part $\mathrm{C}$ contains the soft filament PET, tinsel thread and more fancy yarns. It shows that the more hairiness and hair balls are present on the surface of the Part C, displaying that the pilling performance of the jacquard fabrics is obvious deterioration. Part D contains most fancy yarns and the pilling performance in Part D is worst. This phenomenon illustrates that the content of the fancy yarns play a great role on the pilling performance of the jacquard fabrics. The more the fancy yarns is, the worst the pilling performance is.
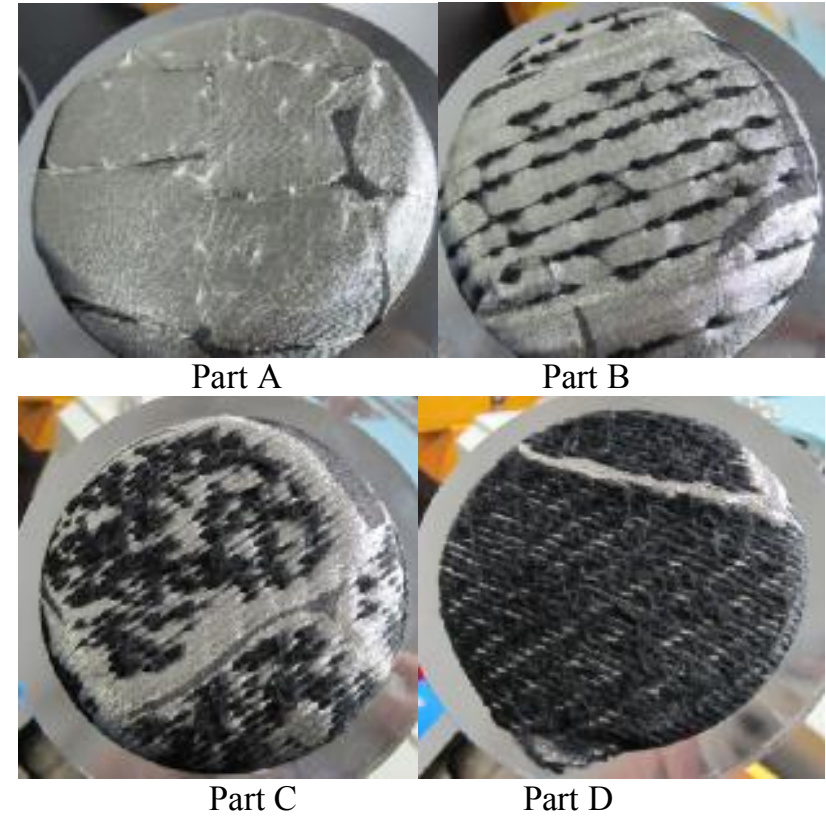

Figure 5: the pilling resistance of the jacquard fabrics in different parts

Heat conductivity, wettability, moisture and air permeability are important factor of evaluating the hotwet comfortability of the fabric. Air permeability is the performance of the gas molecules through the fabric, which decides the warm and windproof of the tent. There are many influence factors on the air permeability of fabric, such as porosity of fiber, pore between fibers or threads and moisture absorption of fiber. Fig . 6 shows the air permeability of the jacquard fabrics in different parts. For all parts of the fabric, the air permeability is no more than $140 \mathrm{~mm}$, and that in Part C and D is less than $120 \mathrm{~mm}$, displaying a better warm and windproof property. There are many factors which can influence the air permeability of the jacquard fabrics, such as fiber, yarn structure, and fabric structure. The reason is that the structure in Part $\mathrm{C}$ and $\mathrm{D}$ is tighter and moisture absorption of tinsel is poor.

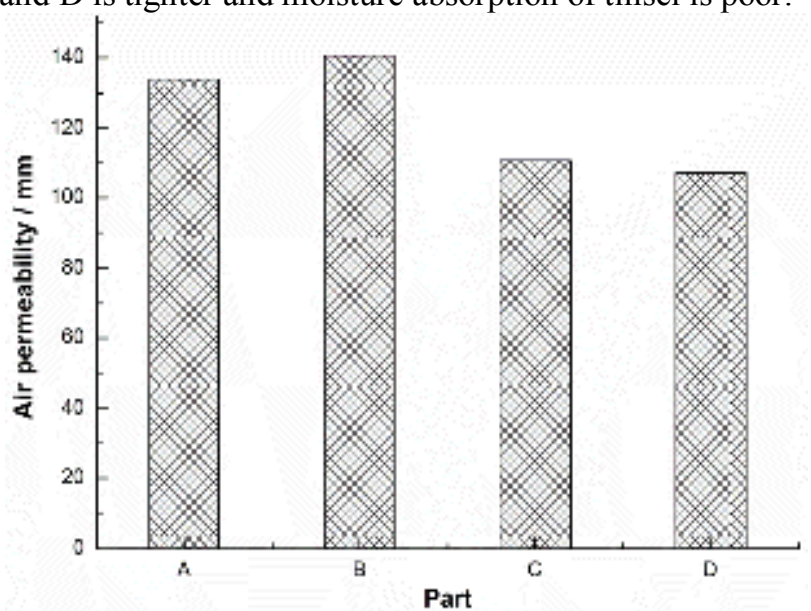

Figure 6: the air permeability of the jacquard fabrics in different parts

\section{CONCLUSIONS}

The mechanical, wear-resisting properties and air permeability of a kind of novel jacquard fabrics with differential warp density for tents were studied. The results showed that the strength of the filament and warp density 
took a great role on the broken strength of the fabric and the order of tensile strength for different part is as follow: $\mathrm{C}>\mathrm{D}>\mathrm{A}>\mathrm{B}$. The bending stiffness of tinsel thread and tensile strength in radial direction played a great role on the bursting strength of the tent, and the bursting strength in Part A made of PET filament showed the maximum value. After friction for 3200 times, the weight loss in Part $\mathrm{A}$ is only about $2.5 \%$, showing an excellent wear-resisting property. However, the weight loss in Part C and D is more than $30 \%$ and $40 \%$, respectively, indicating that the wearresisting property in Part $\mathrm{C}$ and $\mathrm{D}$ is very poor. For all parts of the fabric, the air permeability is no more than $140 \mathrm{~mm}$, and that in Part C and D is less than $120 \mathrm{~mm}$, displaying a better warm and windproof property.

\section{ACKNOWLEDGMENT}

This work was financially supported by the Science and Technology Department of Zhejiang Province Project (2013E90019).

\section{REFERENCES}

[1] Y. Yang, J. Meng, "Discussion on functional fabrics of outdoor sportswear," Melliand China, 11, pp. 63-65, 2010.

[2] Y. Chen, J. Yu, C. Chu, "The present and developing trend of the tent fabrics," Technical Textiles, 12, pp. 26-31, 2004.

[3] Y. Zhang, "Outdoor sportswear fabrics and its application research," Internet fortune, 8, pp. 202-203, 2010.

[4] Y. Zhao, Y. Tang, X. Wang. T. Lin, "Superhydrophobic cotton fabric fabricated by electrostatic assembly of silicananoparticles and its remarkable buoyancy," Applied Surface Science, 256, pp. 6736-6742, 2010.

[5] L. Tie, Z. G. Guo, W. Li, "Optimal design of superhydrophobic surfaces using a paraboloid microtexture," Journal of Colloid and Interface Science, 436, pp, 19-28, 2014.

[6] O. Gutman, M. Natan, E. Banin, S. Margel, "Characterization and antibacterial properties of $\mathrm{N}$-halamine-derivatized cross-linked polymethacrylamide nanoparticles," Biomaterials, 35, pp, 50795087, 2014.

[7] S. Joneydi, A. Khoddami, A. Zadhoush, "Novel superhydrophobic top coating on surface modified PVC-coated fabric," Progess in Organic Coatings, 76, pp, 821-826, 2013.

[8] http://www.chyxx.com/industry/201308/217479.html.

[9] C. Huang, "The comfortable requirements and development of sportswear fabrics," Guangxi Textile Science \& Technology, 38(4), pp. 56-57, 2010.

[10] Y. Liu, Y. Liu, X. Ren, T. S. Huang, “Antimicrobial cotton containing $\mathrm{N}$-halamine and quaternary ammonium groups by grafting copolymerization," Applied Surface Science, 296, pp, 231-236, 2014.

[11] H. B. Kocer, S.D. Worley, R.M. Broughton, T.S. Huang, “A novel N-halamine acrylamide monomer and its copolymers for antimicrobial coatings," Reactive \& Functional Polymers, 71, pp, 561-568, 2011

[12] H. Zhang, S. Zhao, "The study of the properties of high performance sports and outdoor clothing," Tianjing textile Science \& Technology, 1, pp. 17-20, 2006. 